\title{
Experimental study on mechanical properties of aircraft honeycomb sandwich structures
}

\author{
A.A. Zakeri ${ }^{1, \mathrm{a}}$ and H.Talebi Mazraehshahi ${ }^{2}$ \\ ${ }^{1}$ Civil Engineering Department, Golpaygan Islamic Azad University, Golpaygan, Iran \\ ${ }^{2}$ Aerosapce Engineering Department, Sharif University Of Technology, Tehran, Iran
}

\begin{abstract}
Mechanical behaviour of sandwich panels under different conditions have been exprimentally studied in this research to increase the knowledge of aircraft sandwich panel structures and facilitate design criteria for aircraft structures. Tests were concentrated on the honeycomb sandwich structures under different loads including flexural, insert shear, flat wise tension and compression loads. Furthermore, effect of core density and face material on mechanical behavior of different samples were investigated and compared with analytical and FEM method. Effects of skin thickness on strength of honycomb sandwhich panels under shear pull out and moments have also been considerd in this study. According to this investigation, insert strength and flexural test under different load conditions is strongly affected by face thickness, but compression and tearoff (falt wise tensile) properties of a sandwich panel depends on core material. The study concludes that the correlation between experimental results and the analytical predictions will enable the designer to predict the mechanical behaviour and strength of a sandwich beam; however, applied formula may lead engineers to unreliable results for shear modulus.
\end{abstract}

\section{Introduction}

Sandwich structures are composite construction of high strength faces bonded to an intermediate low density core usually honeycombs. The faces are designed for panel tension, compression and inplane shear loads. The core separates the faces, resists transverse shear forces, and provides lateral stability. The strength and stiffness of a sandwich panels are largely affected by the face material, however, its separate elements (faces, core, and attachment) must be sized individually to achieve optimum performance.

The various failure modes in aircraft sandwich panels are described and experimental mechanics methods are used to illustrate the failure modes and verify analytical and FEM predictions.

One of important parameters in design of honeycomb sandwich panels is strength of insert which install prior or after curing process of parts to carry the loads from bolt to the panel. That is why, insert strength against applied loads in addition to joining of the face and core and their attachements must be precisely studied.

a e-mail : zakeri_al@mapna.com

This is an Open Access article distributed under the terms of the Creative Commons Attribution-Noncommercial License 3.0, which permits unrestricted use, distribution, and reproduction in any noncommercial medium, provided the original work is properly cited. 
In this paper, mechanical behavior of sandwich panels under different conditions have been exprimentally studied to increase the knowledge of aircraft sandwich panel structures and facilitate design criteria for aircraft structures. Tests were concentrated on honeycomb sandwich structures under different loads including flexural, insert shear, flat wise tension and compression loads based on standard test methods. Furthermore, effect of core density and face material on mechanical behavior of different samples were investigated and compared with analytical and FEM method. Effects of skin thickness on strength of honycomb sandwhich panels under shear, pull out and moments have also been considerd in this study.

\section{Flexural behaviours}

One of the important parameter for usage of sandwich structures are their flexural behaviours. The flexural properties of sandwich structures are usually affected by facing materials and thickness but core properties is important, because of their effects on deformation and strength of panels with different dimensions. Flexure tests on flat sandwich construction may be conducted to determine the sandwich flexural stiffness, the core shear strength and shear modulus, or the facings compressive and tensile strengths. Tests to evaluate core shear strength may also be used to evaluate core-tofacing bonds. Figure 1, 2 show loang beam and short beam loading which used in satandard method ASTM C-393[1].

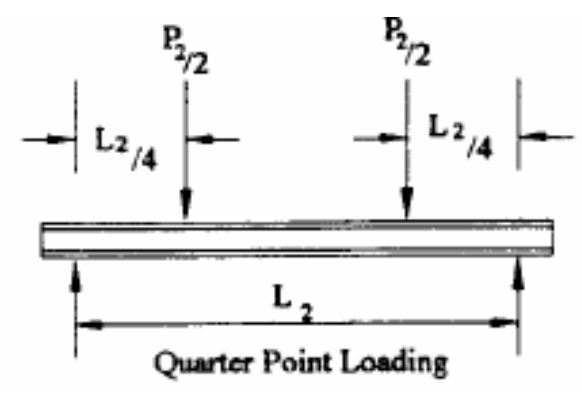

Fig.1. Long beam bending loading

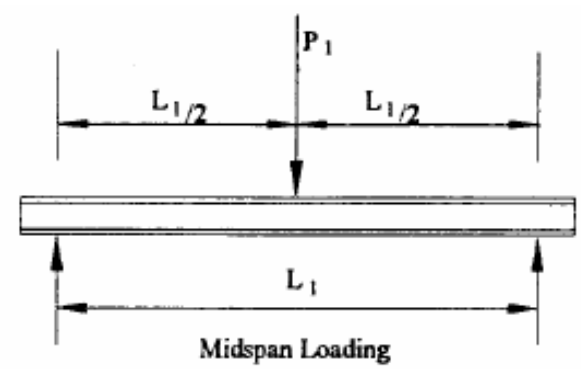

Fig.2. Short beam bending loading

According to this standard following formula are used to calcualte differnet prameter of flexture in sandwich panels .

$$
\begin{gathered}
\tau_{c u}=\frac{P_{1}}{(d+c) b}, \quad \sigma_{f}=\frac{P_{2} L_{2}}{4 t(d+c) b} \\
\Delta_{1}=\frac{P_{1} L_{1}^{3}}{48 D}+\frac{P_{1} L_{1}}{4 U} \\
\Delta_{2}=\frac{11 P_{2} L_{2}^{3}}{768 D}+\frac{P_{2} L_{2}}{8 U} \\
D=\frac{P_{1} L_{1}^{3}\left[1-\left(11 L_{2}^{2} / 8 L_{1}^{2}\right)\right]}{48 \Delta_{1}\left[1-\left(2 P_{1} L_{1} \Delta_{2} / P_{2} L_{2} \Delta_{1}\right)\right]} \\
G=\frac{P_{1} L_{1} c\left[8 L_{1}^{2} / 11 L_{2}^{2}-1\right]}{\Delta_{1} b(d+c)^{2}\left[\left(16 P_{1} L_{1}^{3} \Delta_{2} / 11 P_{2} L_{2}^{3} \Delta_{1}\right)-1\right]}
\end{gathered}
$$




$$
D=\frac{E_{f} b\left(d^{3}-c^{3}\right)}{2}, U=\frac{G(d+c)^{2} b}{4 c}
$$

Where :

$\tau_{c}=$ core shear stress $(\mathrm{MPa}), P_{1}=$ short beam $\operatorname{load}(\mathrm{N}), P_{2}=$ long beam $\operatorname{load}(\mathrm{N}), d=$ sandwich thickness $(\mathrm{mm}), c=$ core thickness $(\mathrm{mm}), b=\operatorname{sandwich}$ width $(\mathrm{mm}), \sigma_{f}=$ facing bending stress(MPa), $t=$ facing thickness $(\mathrm{mm}), L_{1}=$ short beam span length $(\mathrm{mm}), L_{2}=$ long beam span length $(\mathrm{mm})$, $U=$ panel shear rigidity(N), $E_{f}=$ facing modulus(Mpa), $D=$ panel bending stiffness(N-mm^2), $G$ $=$ core shear modulus $(\mathrm{MPa})$ and $\Delta_{1}, \Delta_{2}=$ total beam midspan deflection $(\mathrm{mm})$.

Note also from Eqs (1) and (2) that the core shear stress term is independent of the span length (L), while the bending stresses rises linearly with increasing span. From this, it can be concluded that as the span surges up from zero, the first failure mode to occur will be the shear failure of the core. The next step is to investigate the failure mode above a transition span $\left(\mathrm{L}_{\mathrm{T}}\right)$ [2]. It is known that the tensile strength of the skin is greater than the compressive strength. and that the beam geometry is symmetrically about the centriod. It can he concluded that the skin failure will be in compression. Furthermore it is also known that the core material has a higher compressive strength when compared to its tensile strength. Therefore the core will fail in tension. As the span enlarges, the bending stresses in the skin and core will increase proportionally meanwhile the core shear stress will remain constant.

Long and short baem tests performed for samples which cut from ready panels as Fiberlam 2100Grade3,2[3] from Hexcel company. This panel manufactured from 2 layer of unidirectional glass/carbon fore facing and honycomb HRH10-3-64 for grade 2 and HRH10-3-123 for grade 3. Dimension of samples in this investiagtion tabulated in table 1.

Table 1. Dimension of samples

\begin{tabular}{|l|l|l|l|l|l|}
\hline$L_{1}$ & $L_{2}$ & $b$ & $t$ & $\mathrm{~d}$ & $\mathrm{c}$ \\
\hline 508 & 101.6 & 76.2 & 0.32 & 10.16 & 9.52 \\
\hline
\end{tabular}

Figures 3 to 5 show long and short beam loading graph according to test for samples 2100-Grade3 in $\mathrm{L}$ and $\mathrm{T}$ direction $(\mathrm{L}=$ length of samples are parallel to core ribbon direction $(0), \mathrm{T}=$ length of samples are perpendicular to core ribbon direction(90))

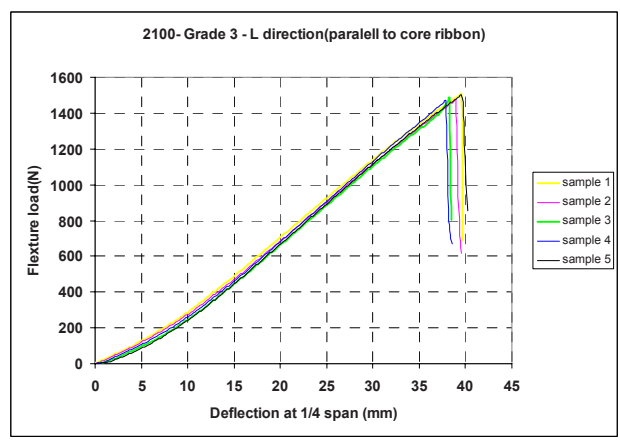

Fig.3. Long beam graph for samples 2100-Grade3-L

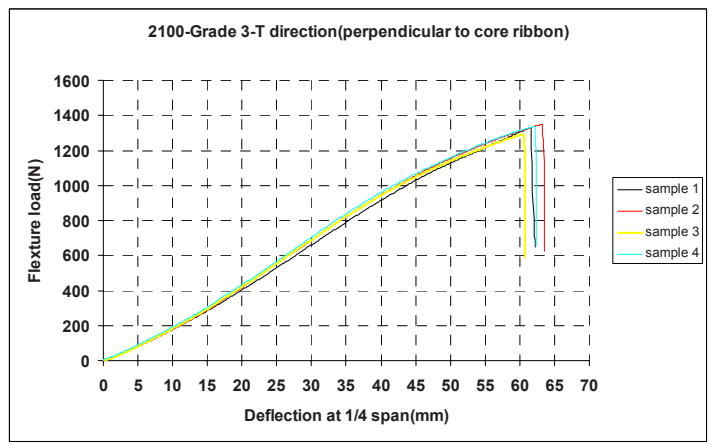

Fig.4. Long beam graph for samples 2100-Grade3-T 


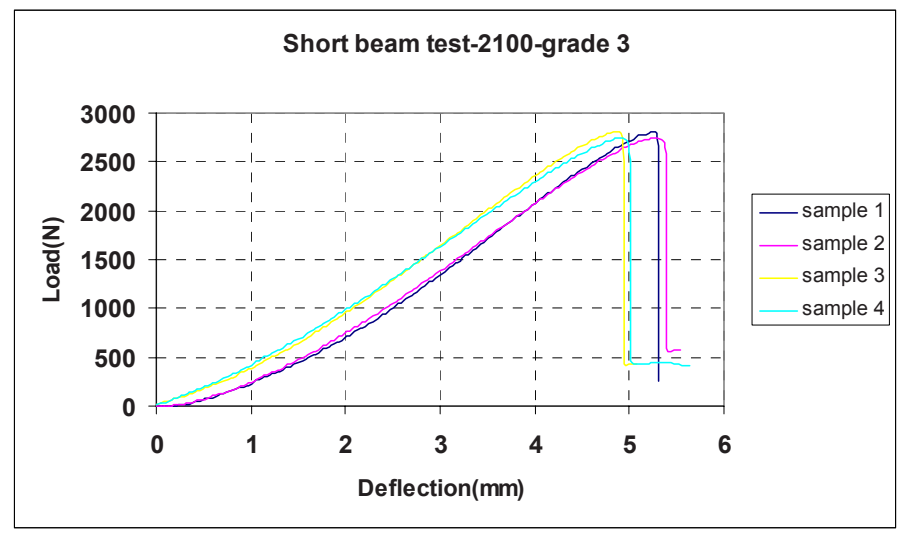

Fig.5. Short beam graph for samples 2100-Grade3-T

For each panel, all flextural properies were calculated and then used in FEM analysis. Tables 2 to 5 show the results for mentioned panels for testing the samples. Comparing of calculated shear modulus of core from tests according to equation 5 with real values as specified in material data sheet, apeares that calculated shear modulus in $\mathrm{L}$ and $\mathrm{T}$ direction are not correctly coincided with real as in Table 3. That is why the calculation of this property is very sensitive to $\Delta_{1}$ from test. This error appear also on detremination of $\mathrm{D}$ and $E_{f}$ but it is small. For solving this problem it is recommended that shear modulus $(G w, G L)$ of core detremined by another standard method ASTM C273[4] instead equation 5, and then used in equations 3 and 6 for detremination of D and $E_{f}$. In this study, $G w, G L$ was used according to data sheet of honycomb, but if core type is unknown, standard test method ASTM C273 must be used to determine these paramters. As shown in Table 4, error in $\Delta_{2}$ is small, beacuse long beam displacment is mostly the result of bending and effect of core, but $\Delta_{1}$ error is big and this is also due to shear modulus, however, effect of this error on ultimate compressive strength of the facing $\left(\sigma_{f u}\right)_{c o m p}$ and core shear strength $\left(\tau_{c u}\right)$ is small.

Table 2. Mid span displacement and load at long and short beam test

\begin{tabular}{|c|c|c|c|c|}
\hline \multirow{2}{*}{$\begin{array}{c}\text { Samples } \\
\text { name }\end{array}$} & \multicolumn{2}{|c|}{ Long beam } & \multicolumn{2}{c|}{ Short beam } \\
\cline { 2 - 5 } & $P_{2}$ & $\Delta_{2}(\mathrm{~mm})$ & $P_{1}$ & $\Delta_{1}(\mathrm{~mm})$ \\
\hline Grade3-L & 1488.8 & 53.43 & 4380.3 & 4.8 \\
\hline Grade3-T & 1328.7 & 83.57 & 2774.2 & 5.07 \\
\hline Grade2-L & 1227.8 & 47.40 & 2577.8 & 6.4 \\
\hline Grade2-T & 1002.1 & 61.16 & 1288.9 & 5.81 \\
\hline
\end{tabular}

Table 3. Flexural properties of samples

\begin{tabular}{|l|c|c|c|c|c|c|}
\hline \multirow{2}{*}{$\begin{array}{c}\text { Samples } \\
\text { name }\end{array}$} & \multicolumn{2}{|c|}{$\mathrm{N}-\mathrm{mm}^{\wedge} 2$} & \multicolumn{2}{c|}{$\mathrm{MPa}$} & \multicolumn{2}{c|}{$\mathrm{GPa}$} \\
\cline { 2 - 7 } & $\mathrm{D}$ (test) & $\mathrm{D}($ real $)$ & $\mathrm{G}($ test $)$ & $\mathrm{G}($ real $)$ & $E_{f}$ (test) & $E_{f}$ (real) \\
\hline Grade3-L & $5.57 \mathrm{e}+07$ & $5.39 \mathrm{e}+7$ & 46.91 & 100 & 46.92 & 45.67 \\
\hline Grade3-T & $3.13 \mathrm{e}+07$ & $3.05 \mathrm{e}+7$ & 29.02 & 60 & 26.66 & 26.02 \\
\hline Grade2-L & $5.63 \mathrm{e}+07$ & $5.04 \mathrm{e}+07$ & 15.6 & 63 & 48.03 & 42.95 \\
\hline Grade2-T & $3.67 \mathrm{E}+07$ & $3.20 \mathrm{E}+07$ & 8.36 & 35 & 31.26 & 27.29 \\
\hline
\end{tabular}


14th International Conference on Experimental Mechanics

Table 4. Comparison of displacement based on test and FEM results

\begin{tabular}{|c|c|c|c|c|c|c|}
\hline \multirow{2}{*}{$\begin{array}{c}\text { Samples } \\
\text { name }\end{array}$} & $\Delta_{2}(\mathrm{~mm})$ & $\Delta_{1}(\mathrm{~mm})$ & $\Delta_{2}(\mathrm{~mm})$ & $\Delta_{1}(\mathrm{~mm})$ & $\Delta_{2}(\mathrm{~mm})$ & $\Delta_{1}(\mathrm{~mm})$ \\
\cline { 2 - 7 } & \multicolumn{2}{|c|}{ test } & \multicolumn{2}{c|}{ FEM-test data } & \multicolumn{2}{c|}{ FEM-real GW or GL } \\
\hline Grade3-L & 53.43 & 4.8 & 53.14 & 7.5 & 53.1 & 5.58 \\
\hline Grade3-T & 83.57 & 5.07 & 82.96 & 7.88 & 83 & 5.98 \\
\hline Grade2-L & 47.406 & 6.4 & 47.17 & 8.87 & 50.3 & 4.15 \\
\hline Grade2-T & 61.16 & 5.81 & 60.88 & 7.83 & 64.8 & 3.38 \\
\hline
\end{tabular}

Table 5. Comparison of face and core strength based on test and FEM results

\begin{tabular}{|c|c|c|c|c|c|c|}
\hline \multirow{2}{*}{$\begin{array}{c}\text { Samples } \\
\text { name }\end{array}$} & $\left(\sigma_{f u}\right)_{c o m p}$ & $\tau_{c u}$ & $\left(\sigma_{f u}\right)_{c o m p}$ & $\tau_{c u}$ & $\left(\sigma_{f u}\right)_{c o m p}$ & $\tau_{c u}$ \\
\cline { 2 - 7 } & \multicolumn{2}{|c|}{ test } & \multicolumn{2}{c|}{ FEM-test data } & \multicolumn{2}{c|}{ FEM-real GW or GL } \\
\hline Grade3-L & 393.91 & 2.9 & 394 & 3.17 & 394 & 3.35 \\
\hline Grade3-T & 351.54 & 1.85 & 351.01 & 1.96 & 351.03 & 2.05 \\
\hline Grade2-L & 324.86 & 1.7 & 325 & 1.79 & 327 & 1.93 \\
\hline Grade2-T & 265.13 & 0.86 & 265 & 0.88 & 267 & 0.93 \\
\hline
\end{tabular}

\section{Insert behaviour}

Insert are bonded in sandwich construction core and used to transfer loads to sandwich constructions. The insert is embedded in potting materials, generally with a cylindrical shape. The potting shall be capable to transfer loads from the insert into the core. The typical insert configuration and applied loads is shown in fig 6. Loads which apply on insert are: insert shear force, pullout load, bending moment and torque.

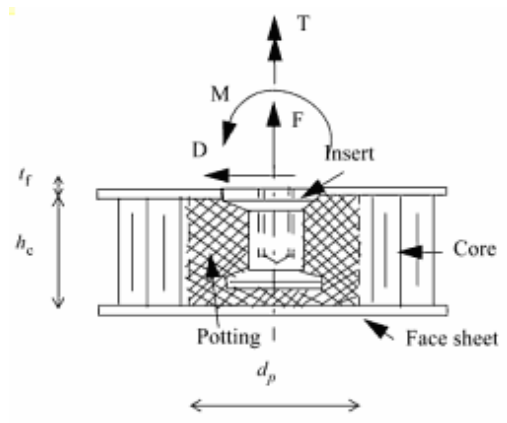

Fig.6. Geometry of insert

\subsection{Insert shear behaviour}

Insert shear performed according to BMS 4-20 as shown in Figure 7. This testing performed on two ready panel Fibrelam 1200 grade 5,6[5]. these panels has same 2 layer glass fabric type 181 as facing and HRH10-3-80 honeycomb with $80 \mathrm{~kg} / \mathrm{m}^{3}$ density for grade 5 and HRH10-3-48 honeycomb with $48 \mathrm{~kg} / \mathrm{m}^{3}$ density for grade 6 as core material. The results for this test is can be seen in Figure 8 for Fibrelam 1200 grade 6 with panel thickness of $19.2 \mathrm{~mm}$. 


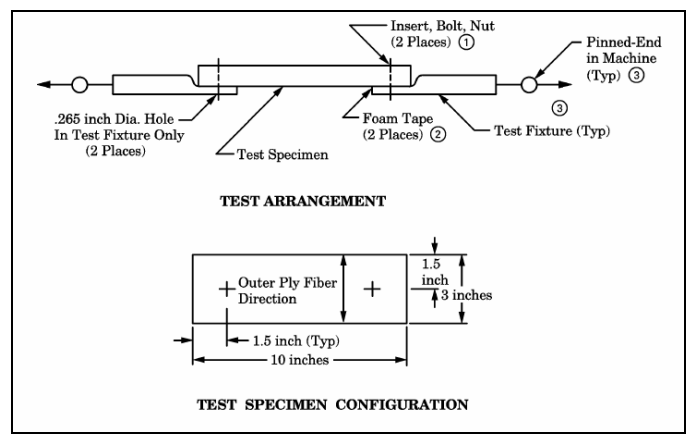

Fig.7. Insert shear arrangement

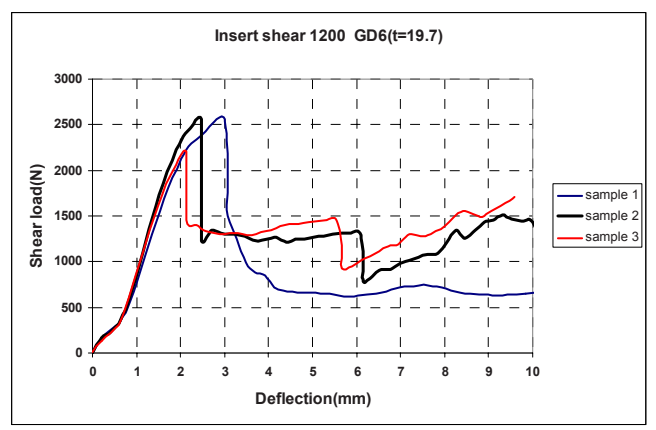

Fig.8. Insert shear results for panel 1200-grade 6(t=19.7 mm)

According to test evidences, maximum insert shear load occurs when the facing materials fails due to compressive failure, and after that load suddenly reduced and then shear failure in facing and core is predominant. An approximate method for prediction of insert shear load $F_{s}$ is based on maximum bearing strength of laminate [6]:

$$
F_{s}=\sigma_{b r f} \times t \times D
$$

Where:

$\sigma_{b r f}$ is ultimate bearing strength of face, $t$ is laminate or face thickness and $D$ is insert outer diameter .

Table 6 shows the insert shear load for different panels and comparison with predicted loads.

Table 6. Comparison between insert shear load predicted and test result

\begin{tabular}{|c|c|c|c|c|c|}
\hline Samples name & $\mathrm{t}(\mathrm{mm})$ & $\sigma_{\text {brf }}(\mathrm{Mpa})$ & $\mathrm{D}(\mathrm{mm})$ & $F_{s}$ (test) $(\mathrm{N})$ & $F_{s}$ (predicted)(N) \\
\hline $\begin{array}{c}\text { Fibrelam 1200 grade 6 } \\
(\mathrm{t}=19.7)\end{array}$ & 0.55 & 227 & 7.25 & 2460 & - \\
\hline $\begin{array}{c}\text { Fibrelam 1200 grade 6 } \\
(\mathrm{t}=10.2)\end{array}$ & 0.55 & 227 & 7.25 & 1772 & 1810 \\
\hline $\begin{array}{c}\text { Fibrelam 1200 grade 5 } \\
(\mathrm{t}=10.2)\end{array}$ & 0.55 & 227 & 7.25 & 1848 & 1810 \\
\hline
\end{tabular}

For Fibrelam 1200 grade $6(\mathrm{t}=19.7)$ samples predicted $F_{s}$ was not calculated because insert is not fully potted and this approximately method can not be used for this case. 


\subsection{Insert pull out behaviour}

Pull out load is another criterion which must be considered in calculation of strength in sandwich and laminated composite part. Pullout strength depends strongly on head of insert or fastener in composite parts, because pull out load apply perpendicular to plane of composite parts. An approximate method in the most of industries is as follow[7]:

$$
F_{\text {pullout }}=\pi \times D_{\text {head }} \times t \times I L S S
$$

Where $D_{\text {head }}$ Fastener head diameter, $\mathrm{t}$ is thickness of laminate and ILSS is interlaminar shear strength. This formula has good accuracy for laminated composites part but it is not very accurate for sandwich structures. For sandwich structures, it is recommended to perform testing on some samples with same insert configurations and faces thickness $\left(t^{\text {refrence }}\right)$, then according to following formula calculate pull out strength for different thickness of faces and for different materials:

$$
F_{\text {pullout }}=F_{\text {pullout }}^{\text {refrence }} \times \frac{I L S S}{I L S S^{\text {refrence }}} \times \frac{t}{t^{\text {refrence }}}
$$

Where: $F_{\text {pullout }}^{\text {refrence }}$ is pullout strength of reference samples is manufactured of facing material with thickness $t^{\text {refrence }}$ and interlaminar shear strength ILSS refrence.

According to equation 9, making thicker facing, elevates pullout strength and also ILSS of facing material is very important. Also it can be seen with adding increasing of core thickness, pullout strength increases. There is no test results for this subject from authors in this research.

\section{Compression behaviour}

Some tests were performed on samples from HRH10-3-48, HRH10-3-64 and HRH10-3-123 to investigate compressive behaviour of sandwich structures. Figure 9 shows result of those tests. As it can be seen in graph, compressive strength of core moves up as density of core increases. Experiences show that face has no effect on compressive strength of sandwich.

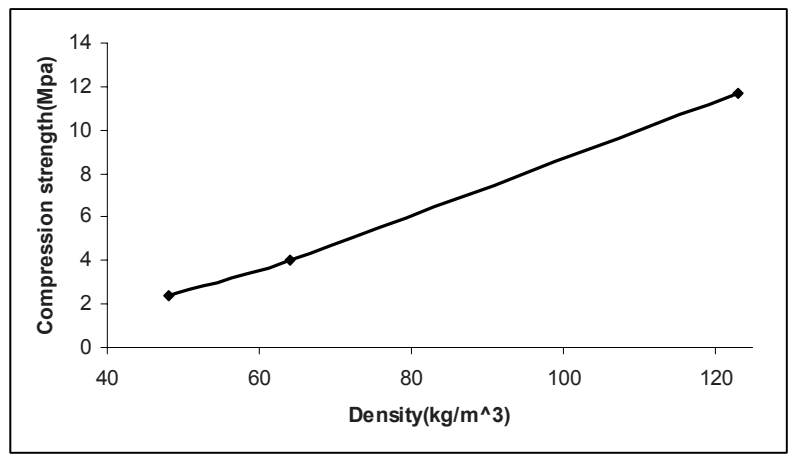

Fig.9. Effect of core density to compression strength

\section{Flatwise behaviour}

Although, flatwise tensile test is not important for strength and stiffness evaluation of the structure, however it plays an important role in assembling and checking of bonding of face to core during curing process in sandwich structures. To evaluate the accuracy of bonding of face to core, 
tensile failure of sandwich shall be occurred in core part. Figure 10 shows heavy core has more strength than light cores.

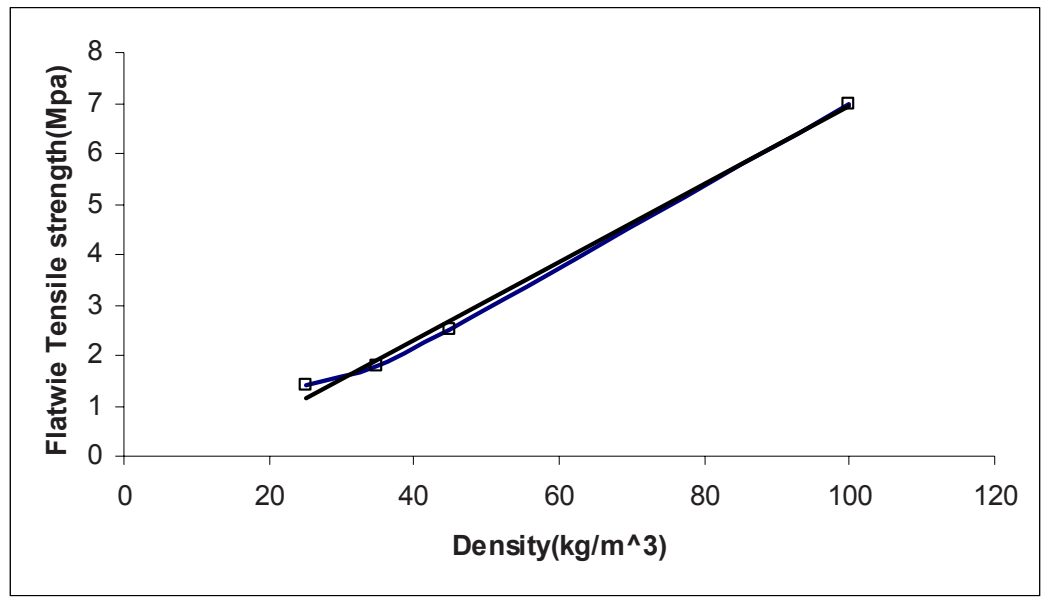

Fig.10. Effect of core density to flatwise tensile strength

\section{Conclusion}

According to this research, insert strength and flexural test under different load conditions is strongly affected by face thickness, but compression and tearoff (flat wise tensile) properties of a sandwich panel depends on core material. The study concludes that the correlation between experimental results and the analytical predictions will enable the designer to predict the mechanical behaviour and strength of a sandwich beam. Investigation shows that using related regular formula encounter big errors in calculating shear modulus where they strongly differ from real values.

\section{References}

1. ASTM C393, Standard Test Method for Flexural Properties of Sandwich Constructions, Annual Book of ASTM Standards, Volume 15.03(2000).

2. Nicholas N.Jise, Clement Hiel and Ori Ishai, Mechanical Performance of Composite Sandwich Beams With Syntactic Cores, Composite Materials Testing and Design, Twelfth Volume, ASTM STP 1274, R. B. DEo and C.R. Scaff, Eds. American Society for Testing and Materials, pp.125138,(1996).

3. Fiberlam2100 GD-2,3, Data Sheet, Hexcel Composites, F.R.

4. ASTM C273, Standard Test Method for Shear Properties of Sandwich Core Materials, Annual Book of ASTM Standards, Volume 15.03(2000).

5. Fiberlam1200 GD-5,6, Data Sheet, Hexcel Composites, F.R.

6. D.E. Fox and K.W. Swaim, Static Strength Characteristics of Mechanically Fastened Composites Joints, NASA/TM-1999-209735, Marshall Space Flight Center, Albama(1999)

7. Bombardier Aerosapce, Crj200 Upper-Mid And Vertical Stabiliser Aft Fairings SRM Damage Allowable Justification(2005). 